\title{
Más acá de la imagen-simulacro: anotaciones metodológicas
}

\section{Before of the image-simulacra: methodological annotations}

\author{
José M. Santa Cruz G. \\ Universidad Arcis \\ josesantacruzgrau@gmail.com
}

\begin{abstract}
Resumen El objeto de este artículo es exponer el mapa conceptual del libro «Imagen-simulacro: estudios de cine contemporáneo (1)» (2010). Con ello, daremos cuenta de una estrategia particular de investigación sobre cine contemporáneo en Chile y, a su vez, problematizaremos cómo pensar el cine y el audiovisual en la contemporaneidad. Para ello profundizaremos en una serie de problemas teóricos que articularon la investigación y constituyeron la condición de posibilidad para la categoría Imagen-simulacro. Estos son: qué entendimos por lo contemporáneo y por lo cinematográfico; desde qué lugar pensar la tensión entre cine moderno y contemporáneo; y, por último, cómo el concepto de Imagen-simulacro se relaciona con otros conceptos similares que buscan definir la contemporaneidad del cine.
\end{abstract}

Palabras clave Lo contemporáneo; Lo cinematográfico; Cine moderno; Cine contemporáneo; Imagen-simulacro

Abstract The purpose of this article is to expound the conceptual map of the book «Image-simulacra: studies of contemporary cinema» (2010). By this, we'll realize the particular research strategy developed in contemporary cinema in Chile and, at the same time, problematize about how to think the contemporary cinema and audiovisual. For this, we'll go into some theorical problems that articulated the research and constituted the condition possibility to build the category Image-simulacra. These are: what we understood for contemporary and cinematographic fields; from what place to think about the tension between modern and contemporary cinema; and, finally, how the concept of Imagesimulacra is related to another similar concepts that seek to define the contemporary of cinema

Keywords Contemporary; Cinematographic fields; Modern cinema; Contemporany cinema; Image-simulacra 


\section{Introducción}

Este artículo es producto de dos charlas desarrolladas durante el año 2010, que llevaron por título «Nuevos horizontes del cine contemporáneo», en las cuales se profundizo en la estrategia investigativa (metodológica y conceptual) que dio origen al libro «Imagen-simulacro, estudios de cine contemporáneo (1)» $(2010)^{1}$. La primera se realizó en la Escuela de Comunicación Audiovisual del Duoc UC-Concepción y la segunda en la cátedra de Cultura Visual del Instituto de Comunicación e Imagen-ICEI de la Universidad de Chile. En el contexto del número monográfico sobre los estudios de cine en Chile y Latinoamérica, nos parece importante, para intentar construir algo así como un «estado del arte» de los estudios cinematográficos en la actualidad, exponer una estrategia investigativa particular realizada en un contexto teórico-social específico, que nos posibilita hacer visible las discusiones conceptuales que cruzaron el libro y entender a éste como una caja de resonancia de problemas que cruzan el campo cinematográfico local y regional. Tomando en cuenta que una de las discusiones fundamentales alojadas en la investigación, fue la problematización del estatus de lo cinematográfico (entendido como el problema teórico del cine) en el régimen contemporáneo del arte, es decir, cómo pensar el cine y el audiovisual en tensión con una serie de prácticas artísticas y cómo delinear su campo de estudios en la contemporaneidad. Por último, es pertinente incorporar, que la exposición de una estrategia metodológica y conceptual hace evidente la posición política que reclama esa palabra inscrita, ahí cuando intentando acercarse al objeto borra las condiciones de posibilidad de su inscripción, en esa puesta en evidencia se juega este escrito.

Al construir la categoría de Imagen-simulacro, la cual tenía por objeto abarcar una serie de prácticas audiovisuales de variada índole al interior del campo cinematográfico-audiovisual en las últimas décadas, frente a nosotros se nos puso la tarea de cómo pensar aquello que está sucediendo en el presente cinematográfico, cómo identificar lo contemporáneo y su especificidad en el cine. Tarea que se sostenía en una pregunta anterior, por qué intentar aprehender el presente de un proceso que aún no ha expresado su contundencia, tomando las precarias herramientas conceptuales que siempre tiene la teoría para pensar el presente, insuficiencia que no está determinada por la carencia de densidad reflexiva, sino porque el presente siempre se escabulle a la palabra que intenta definirlo. Y la respuesta que intentamos expresar, es que lo contemporáneo no es el resumidero de lo actual, en este caso,

1 Investigación financiada por el Fondo Audiovisual, línea de investigación y capitación (2009). 
el catastro de las piezas cinematográficas-audiovisuales que se hacen en el presente, sino lo contemporáneo es un dispositivo de análisis teórico.

El filósofo Giorgio Agamben, en una breve exposición en el seminario de filosofía teorética que dictó en la Facultad de Artes y Diseño de la Universidad de Venecia los años 2006 y 2007, titulada «¿Qué es lo contemporáneo?» (2008: $\mathrm{s} / \mathrm{n}$ de pp.), reflexionó en qué medida se configura lo contemporáneo como dispositivo de análisis teórico, qué estrategia persigue un análisis que parte desde el imperativo contemporáneo. Agamben pensando a Friedrich Nietzsche propondrá como punto de partida que lo contemporáneo es un acto intempestivo, donde el individuo que está devorado por la cultura histórica se detiene a pensar su presente, quebrando la naturalización del devenir histórico del tiempo. "Es realmente contemporáneo aquel que no coincide perfectamente con [el presente] ni se adapta a sus pretensiones, $[\ldots]$ justamente a través de esta diferencia y de este anacronismo, éles capaz más que los demás de percibir y entender su tiempo". Esta interrupción temporal es un ejercicio activo donde "la contemporaneidad es esa relación singular con el propio tiempo, que se adhiere a él pero, a la vez, toma distancia de éste. [...] Aquellos que coinciden completamente con la época, que concuerdan en cualquier punto con ella, no son contemporáneos pues, justamente por ello, no logran verla, no pueden mantener fija la mirada sobre ella”. La mirada se posa ahí donde el presente se oculta, "contemporáneo es aquel que tiene la mirada fija en su tiempo, para percibir no la luz sino la oscuridad. Todos los tiempos son, para quien experimenta la contemporaneidad, oscuros. Contemporáneo es, justamente, aquel que sabe ver esta oscuridad”.

Lo contemporáneo se configura en el acto intempestivo que interrumpe la temporalidad del presente para posar la mirada en su oscuridad. Esto no quiere decir, que exista en la contemporaneidad una imposibilidad de ver la luz, es decir, la acción pasiva por falta de dicha cualidad, sino es la acción activa de no cegarnos con los brillos y resplandores del tiempo presente. La oscuridad es también materialidad que constituye el presente pero se retrotrae, Agamben lo ejemplificará, a través de los estudios contemporáneos de astrofísica, que proponen que toda la oscuridad que vemos en un cielo estrellado, es causada por la velocidad vertiginosa de las galaxias que se alejan de nosotros, que impide que sus luces nos alcancen. "Percibir en la oscuridad del presente esta luz que trata de alcanzarnos y no puede hacerlo, esto significa ser contemporáneos”. Pero también esta oscuridad es la materia oscura que articula el universo, en una especie de una gran red producida por el movimiento de las galaxias.

Colocar la mirada ahí, entre esa luz que se escapa y una materialidad que articula las luces del presente, es una cita a la cual uno nunca llegará a la hora, será por eso que el dispositivo contemporáneo "se inscribe en el presente y lo marca, 
ante todo, como arcaico, y sólo quien percibe en lo más moderno y reciente los indicios y las marcas de lo arcaico puede ser contemporáneo”. Lo arcaico no como el origen de un pasado cronológico, una fuente de la verdad a la cual llegar y encontrar todas las respuestas, sino como el pasado condiciona y transforma el presente. Y, desde ahí, Agamben propone un último movimiento, tras la acción activa de mirar la oscuridad e identificar esa luz incierta que se nos escapa, interrumpe el tiempo presente para ponerlo en relación con otros tiempos, "de leer de forma inédita la historia, de «citarla»según una necesidad que no proviene de ninguna manera de su arbitrio sino de una exigencia a la que él no puede responder”. Lo intempestivo de lo contemporáneo no será la mera fractura del presente, sino que a través de ello establecer un diálogo entre el pasado y el presente, donde el pasado, afectado por la sombra del presente, "adquiriera la capacidad de responder a las tinieblas del presente".

Nuestra investigación respondió como empeño teórico a aquello que Agamben entiende por el dispositivo contemporáneo, no por poseer la capacidad de saber ver el presente más que ningún otro, sería abusivo plantearnos así, sino en la necesidad de interrumpir el tiempo naturalizado del cine, que ha encontrado una teoría que lo reproduce para hacerlo brillar en sus festivales, circuitos de distribución y comercialización, en sus revistas de crítica especializada o de prensa, esos múltiples haz de luces que ciegan aquello que lo interpela, esa oscuridad de operaciones en los filmes y piezas audiovisuales, que no pueden ser aprehendidos en la ideología del autor, del cine moderno y la cinefilia, objetos que piensan lo cinematográfico aunque se distancien de las lógicas propias del cine. Apagar la luz del proyector y comenzar a ver aquello que deja la imagen cinematográfica contemporánea.

Dentro de la amplitud textual del texto existen dos problemas generales que lo cruzan y determinan, el primero es qué entender por lo cinematográfico, el segundo es cómo pensar la brecha entre cine moderno y contemporáneo. En relación a lo primero, ¿lo cinematográfico será todo aquello que le compete al cine, sintetizando en un mismo gesto los problemas geopolíticos de producción con las decisiones que un postproductor toma en un filme, donde, finalmente, lo cinematográfico sería equivalente al campo del cine? En la investigación, entendimos lo cinematográfico como aquel problema teórico que fue imaginado por el cine, tanto antes de la aparición misma del dispositivo creado por los hermanos Lumière, como lo analiza Jacques Rancière en el prólogo de su texto «La fábula cinematográfica» (2001), como a su vez, los que inaugura en su devenir durante el siglo XX. Lo cinematográfico se articula cuando al cine se lo entiende como «objeto teórico» del arte, cuando se edifica en torno a una 
idea del arte. En esta medida, lo cinematográfico no es un problema que le sea pertinente solamente al cine sino al régimen del arte.

Desde aquí ensayamos un enfoque de trabajo afín al realizado por la teórica del arte Rosalind Krauss en «Lo fotográfico. Por una teoría de los desplazamientos» (1990), en el cual problematiza las implicancias que la aparición de la fotografía provocó en la historia del arte, para ello no sólo se concentró en el análisis de fotografías y fotógrafos, sino en la dimensión conceptual de lo fotográfico en un campo de estudio expandido, donde la puesta en crisis del estatuto del autor y la introducción del signo índice se transformaron en problemas a resolver por el arte, tanto en las obras como en los textos que intentaban aprehenderlas. Nuestro trabajo lo entendimos cercano pero no igual al de Krauss, cuando la historia del arte no fue nuestro norte, sino cómo el arte fabula las poéticas de lo sensible. Entonces no sólo expandimos la estrategia de investigación sino también su campo de influencia, su espacio operativo y despliegue de significación. Pero incorporamos la misma precaución a tono personal que tuvo Krauss al pensar lo fotográfico, "si no me siento totalmente satisfecha con este proyecto crítico sobre el objetivo fotográfico [cinematográfico], es porque la fotografía [el cine] es un objeto teórico que reacciona de forma reflexiva sobre el proyecto crítico y sobre el proyecto histórico que lo tratan” (2002: 16-17). Esto nos permite plantear el segundo momento de lo cinematográfico, y que le dará coherencia a lo expresado anteriormente, pensamos al cine como «objeto teórico» dual, ya que al mismo tiempo que los filmes y piezas audiovisuales desarrollan sus formas, discursos y estrategias de significación están proponiendo las categorías y marcos conceptuales para su interpretación.

Desde ahí, se nos hizo necesario ingresar campos conceptuales que han sido constantemente silenciados por una teoría del cine que ha apuntado a su autonomía reflexiva, desde la semiótica y la reflexión textual, de la sociología y la reflexión simbólica, y por último, desde la ideología del autor y la especificidad como medio, todo esto justificado bajo la sospecha que el arte de masas -cineinstaló frente al arte de elite - bellas artes-. Al poner a lo cinematográfico en diálogo franco con campos como la teoría del arte o los estudios visuales contemporáneos, nos permitió generar un campo conceptual expandido, ya que los filmes y piezas audiovisuales contemporáneas proponen problemas que no se pueden abordar completamente con las categorías y conceptos heredados desde el cine moderno, pero aún más, en la medida en que lo cinematográfico ha apuntado a configurar en su desarrollo nuevas formas de entender el arte y el desarrollo simbólico de las sociedades.

Es por esto que consideramos que la reflexión en lo cinematográfico contemporáneo, no puede ser entendido como el mero anecdotario de las 
operaciones estéticas de algunos filmes, como se puede encontrar en «Nuevos cine, nueva crítica: el cine en la era de la globalización» (2006), compilado por Antoine de Baecque, que cristaliza el plan programático de la revista francesa Cahiers du cinema en torno al problema de «la política de autores» y la edificación autorreferencial del cine, desde los postulados godardianos y bazinianos. O el territorio de conceptos que se adhieren al cine, como en $«$ La pantalla global» (2009), de Gilles Lipovetsky y Jean Serroy, en el que se organiza el cine mundial en la simbolización de cuatro grandes estados de la modernidad leída por la filosofía de Lipovetsky. Sino se debe repensar críticamente sus dispositivos de análisis, crítica y lectura; incorporar objetos teóricos que tensionan los límites de lo cinematográfico; reevaluar los silencios y censuras heredades desde el cine clásico y moderno; encontrar genealogías y narraciones que se propongan imaginar " [...] contra el consenso otras formas de «sentido común», formas de sentido común polémico” (Rancière, 2010: 77). Fijando la mirada ahí donde se administra el campo interpretativo de los discursos, problemas estéticos y rendimientos formales, comprendiendo que "[... ] un filme es una singularidad operatoria, ella misma captada en el proceso masivo de una configuración de arte. Un filme es un punto-sujeto para una configuración” (Badiou, 2005: 19).

Para abarcar el segundo problema que trazó el texto, era necesario pensar la contemporaneidad de lo cinematográfico en la confrontación del cine contemporáneo frente al cine moderno desde varias líneas de lectura. La primera, y más evidente, fueron evaluar las consideraciones que el filósofo Gilles Deleuze, en sus estudios sobre cine -«Imagen-Movimiento» (1983) e «Imagen-Tiempo» (1985) - hizo a propósito de la especificidad que el cine lograría cuando la imagen quiebra la relación mimética entre imagen y sonido, suspende la narratividad audiovisual y permite el ingreso del tiempo en la imagen, en lo que éste entenderá como su gravedad reflexiva. Frente a esto, trabajamos que el cine contemporáneo desde la consolidación de la producción de las plataformas digitales, ha planteado ya no una reflexión sobre el tiempo sino sobre la apariencia, entendiendo a ésta como una construcción discursiva del presente, de la realidad, del pasado y de lo imaginario. Al mismo tiempo, que encontramos que era necesario llevar a cabo una revisión de la gravedad temporal deleuzeana del cine moderno, a través de una reflexión que incorpore una audiovisualidad multitemporal que se haga cargo de las distintas formas de habitar el mundo, temporalidades en conflicto y en reconfiguración con densidades históricas muy distintas.

La cristalización de la apariencia en su densidad reflexiva cinematográfica que terminará en la emergencia de las plataformas digitales, comenzó a tomar 
forma cuando la imagen colocó en su ceno la reflexión de su propio estatuto de imagen, en lo que se ha denominado: cine posmoderno. En plena década de los ochenta hubo una explosión de los ejercicios de cita, pastiche o parodia que relegaron la referencialidad cinematográfica a un mero dispositivo ideológico, la imagen se veía más que nunca así misma como su último horizonte de sentido. Lo interesante a resaltar es que esta referencialidad fílmica no es el padecimiento de una tradición, como si acontece en los géneros en el cine clásico o en la tradición pictórica desde el primer renacimiento hasta el impresionismo, tampoco es la superación de una operación como podemos encontrar en las vanguardias pictóricas y menos será la puesta en crisis del estatuto del autor-creador como fue reflexionado la posmodernidad en las artes visuales, la literatura, las artes escénicas, etcétera. Sino por lo contrario, es la mera referencia por la referencia, es la constatación de la imposibilidad de sostener un diálogo con la realidad y lo social, es la última estrategia autoral, ahí donde el director se transforma en el administrador de la memoria cinematográfica-audiovisual del espectador.

El segundo momento de confrontación fue a través del problema del signo indicial, entendido éste como aquel que dota a lo cinematográfico una relación existencial con la realidad, por fuera de la intervención de la subjetividad e individualidad. Esta reflexión edificó gran parte del cine moderno pensado por André Bazin, el cual a través del concepto de inconciente óptico fotográficocinematográfico, instaló que por debajo de toda la espectacularización del cine de Hollywood, se mantenía latente un índice de indeterminación humana que posibilitaba padecer la emergencia de la realidad. Tras la crisis que le propuso el posestructuralismo al concepto de realidad como un todo estable a disposición de la razón y su proyecto moderno, es decir, la subjetividad, este índice de indeterminación fue leído como la posibilidad que emergiera lo real, aquello que desde las reflexiones de Jacques Lacan fue entendido como: todo eso que fue negado para que la realidad, aquella construida por la racionalidad moderna, pudiese desplegarse sobre la materialidad de las cosas, edificando el horizonte de sentido que la constituye.

Esta confianza en la materialidad fílmica-fotográfica en tanto contenedora, primero de la realidad y en un segundo momento de lo real, será puesta en suspenso con la emergencia de las plataformas digitales, justamente cuando se remplaza la materialidad de los haluros de plata por el código binario, ahí donde la luz se transforma en información a traducir por múltiples plataformas de lectura digitales -reproductores de video digital, computadores, celulares, equipos mp4, etcétera-. Con esto no quisimos plantear que el material fílmico tenía la posibilidad de contener la realidad y lo real, y lo digital no, sino que éste último hace evidente la artificialidad de la idea que se sostenía sobre el soporte fílmico. Esta evidenciación nos instala un segundo momento, la verdad como 
convención social se sostuvo durante gran parte de la modernidad en la confianza en la luz. Desde el siglo de las luces hasta el dominio de la ciencia, la luz fue el soporte simbólico de la convención de la realidad como verdad tangible, ejemplo de ello es que la medida específica de un metro es la distancia que recorre la luz en elvacío durante un intervalo de $1 / 299.792 .458$ segundos. Lo que pareciera ir lentamente transformándose hacia un nuevo nivel, ya no es suficiente la luz, sino que además pueda ser transmitible en directo a todo el globo, la verdad como información transferible, repetible y traducible por las diferentes plataformas de información global.

El tercer eje de tensión entre cine moderno y contemporáneo, siendo bastante más periférico a la discusión de los estudios cinematográficos, pero que ha tenido cierta resonancia en el último tiempo, es el problema de la emergencia de los recursos representacionales. En esta dimensión el cine moderno es leído como el cine que pone en evidencia su condición de cine, mostrando en imagen los procesos productivos que lo hacen posible -por ejemplo en el filme E la nave va [Y la nave va] (1983), de Federico Fellini- o cuando expone su condición de ficcionalidad narrativa -por ejemplo Masculin féminin: 15 faits précis [Masculino/Femenino] (1966), de Jean Luc Godard-. Esto se ha sustentado en la idea de que el cine clásico debió naturalizar sus formas narrativas y ausentar sus procedimientos productivos, en la medida en que buscaba la identificación sicológica de los personajes, el despliegue emocional de los conflictos individuales y la concentración discursiva en el contenido implícito de la trama de los filmes. Ahora, ya desde el famoso Sherlock Jr. (1924), de Baster Keaton, podemos encontrar como el cine ha puesto en imagen sus dispositivos de construcción dentro de la narración, cosa que hasta podemos encontrar en una antigua película chilena, La Dama de las Camelia (1947), de José Bohr, sin necesidad de romper con sus pretensiones de identificación emocional y la discursividad implícita de la trama. La puesta en evidencia de los recursos representacionales es parte constituyente del cine, ya que éste corresponde desde su lógica a la modernidad, a diferencia de la pintura o el teatro, que debieron hacer el ejercicio de pensarse dentro de la modernidad, el cine partió desde la autoconciencia representacional que impulsó la modernidad al arte, por ende, no podría por ello constituir un estado epocal del cine, ya que desde ópticas diferentes ha sido un problema que ha padecido desde los embrionarios filmes de George Méliès.

Tras su publicación el texto se confrontó abstractamente con otros simulacros cinematográficos, de variada índoles que apuntaban a especificidades reflexivas muy distintas. La categoría de Imagen-simulacro, que comenzamos a delinear en la investigación «El rostro cinematográfico» (2006- 
2007), se generó desde la lectura crítica del trabajo de Gilles Deleuze y André Bazin sobre la naturaleza fílmica, de la sistematización de los conceptos propuestos por Victor I. Stoichita y Jonathan Crary en torno a los dispositivos representacionales de la modernidad y de la recuperación de las reflexiones de Nietzsche y Georg W. F. Hegel en torno a la condición discursiva de la apariencia (11-30). Esto fue el resultado, como ya planteábamos, de la necesidad de pensar una diferencia, una distancia que no lográbamos resolver con las herramientas que nos ofrecía la teoría cinematográfica. No obstante ello, se presenta interesante contrastar uno de estos otros simulacros con el trabajo que realizamos, uno que en su cercanía reflexiva nos permite hacer visible con mayor nitidez las características y particularidad del ejercicio interpretativo que llevamos adelante.

El teórico del cine Paolo Bertetto ${ }^{2}$, en su artículo «La lágrima y el reflejo. Del análisis a la teoría del film» (2005), desarrolla una lectura del trabajo de Deleuze y de las reflexiones sobre el simulacro de Mario Perinola, para edificar el concepto de imagen-simulacro mientras problematiza la naturaleza fílmica y propone un modelo interpretativo que combina el análisis semiótico y el ejercicio hermenéutico. Bertetto intenta dar cuenta de la especificidad significante de lo cinematográfico al entender que "la imagen fílmica [es] una copia diferencial sin original, o más exactamente, una copia diferencial de una copia diferencial sin original" (19). A su vez, planteará que la imagen-simulacro es una potencia de la imagen cinematográfica, que habita como posibilidad dentro de sus estrategias de significación. "Imagen-devenir, imagen fantasma, imagen simulacro, imagen eidética: son todas cualidades, dimensiones, posibilidades que viven en la imagen fílmica, están ligadas, comprendidas, son inherentes a su estructura esencial" (20). En dicho análisis encuentra que la imagen cinematográfica trabaja "necesariamente y constitutivamente sobre la apariencia, sobre la impresión/ilusión de realidad, sobre el mostrar cualquier cosa que no está en el mundo, pero se parece al mundo" (20). A través de ello, genera una ilusión de realidad que se revela a la apariencia del mundo, donde "la apariencia de verdad que se revela como no verdadero, como falso, es la estructura misma del cine y de la imagen fílmica. La imagen fílmica es la imagen simulacro" (20). Entonces, Bertetto propondrá dos cosas para pensar la imagen simulacro: 1) es una potencia, una estrategia de construcción y de reflexión propia de lo cinematográfico. 2) es la naturaleza esencial del cine.

\footnotetext{
2 Paolo Bertetto actualmente es académico de La Sapienza-Universidad de Roma (Roma 1), es autor y compilador de numerosos títulos entre ellos: El cine de la utopía (1970), Cine, fábrica y vanguardia (1976), Lo peor del mundo: el cine italiano hoy (1982), El enigma del deseo (2001), El espejo y el simulacro. El cine en el mundo convertido en fábula (2007) y La máquina del cine (2010). Ninguno de ellos traducidos al castellano.
} 
Esta idea se consolidará dos años después en su libro «El espejo y el simulacro. El cine en el mundo convertido en fábula» (2007) y que expondrá concisamente en el artículo «La imagen-simulacro»(2008), en los cuales incorpora reflexiones de Nietzsche, Martin Heidegger, Michael Foucault, Jean Baudrillard, entre otros, para dar cuerpo a su doble concepto de imagensimulacro. Bertetto extremará sus argumentos cuando encuentra en la imagen fílmica " $[. .$.$] una genesi demoniaca, come se fosse creata da qualcuno che$ altera le leggi della natura e produce un nuovo «visibile» che si integra al visibile mondano, lo doppia e lo trasforma insieme, creando un altro mondo (audio)visivo di grande forza e pregnanza” ${ }^{3}$ (93). Al mismo tiempo, reforzará la disposición ontológica al comprender que la potencia de la imagen-simulacro está " $[. .$.$] tra il mascheramento del visibile e la sua riformulazione differenziale,$ nell'evocare il mondo per oltrepassarlo, nel mostrarsi come copia apparente e nell'essere insieme similarità ingannevole e differenza dalla copia, integrazione aggiuntiva o sottrattiva della copia, doppio differenziale"4 (101).

Bertetto piensa la simulación, la apariencia y el simulacro desde una distancia que emerge por su búsqueda hermenéutica y que a pesar de que el mismo califica como idealistas-metafísicos a aquellos que defienden la densidad ontológica del cine apegada a su realismo fotográfico: "La pretesa di un rapporto forte tra immagine e originale attesta in ogni modo un fondamento metafisico: lidea che esista un originale e che possa essere materializzato nell'immagine implica un presupposto idealistico e una concezione dell'essere conforme alla tradizione della metafisica occidentale" ${ }^{5}$ (89), termina edificándolos con un mismo prurito idealista. Éste al proponer un cambio de naturaleza en el dispositivo cinematográfico, que desplace la idea de una relación existencial con el original filmado por una relación de simulación, no genera una relación ontológica entre el filme y el objeto filmado, sino de su propio aparato interpretativo con su objeto: el cine. Donde la teoría podría determinar la naturaleza fílmica, lo que terminará clausurando toda materialidad cinematográfica e indiferenciando los matices reflexivos que ésta nos posibilitan.

\footnotetext{
3 “[...] una génesis demoníaca, como si fuese creada por alguien que alterará las leyes de la naturaleza y produce un nuevo «visible» que se integra al visible mundano, lo copia y lo transforma al mismo tiempo, creando otro mundo (audio) visual de gran poder e intensidad". (Todas las traducciones del italiano al castellano son de Juan Carlos Santa Cruz).

4 "[...] entre el enmascaramiento de lo visible y su reformulación diferencial, para evocar al mundo a ir más allá de él, en mostrarse como copia aparente y siendo en conjunto una simulación engañosa y diferencial de la copia, integración aditiva o sustractiva de la copia, doble diferencial". 5 "La pretensión de una fuerte relación entre la imagen y el original revela, en todo caso, un fundamento metafísico: la idea que existe un original que pueda ser materializado en la imagen, implica un presunción idealista y una concepción del ser acorde a la tradición de la metafísica occidental".
} 
En esta medida, podríamos plantear que el problema no radica en optar si la naturaleza del cine es simulacional o representacional, este último en su sentido más conservador, como mimesis de la realidad, sino reconocer la ambigüedad propia de su dispositivo, que es a la simulación y a la representación, lo que es la alquimia a la espiritualismo y a la ciencia. Y es esto lo que conecta internamente al cine con la modernidad como estado epocal, que a diferencia de las bellas artes y lo que devino de ellas durante el siglo XX, es la conciencia de su impureza, no sólo formal y narrativa, como lo piensa acertadamente Rancière, sino también como dispositivo representacional en su sentido contemporáneo, es decir, como un conjunto de consensos simbólicos en una práctica social modificables en el tiempo. Esta ambigüedad no pretende determinar de una vez y para siempre lo que es el cine, sino más bien queda atento a sus posibles transmutaciones. Y en ello radica la potencia de la irrupción de la imagen digital en el cine contemporáneo, ya que logra suprimir la barrera entre simulación y mímesis ratificando la ambigüedad de su dispositivo, al seguir siendo una imagen que puede ser exaltada por la luz, al mismo tiempo, que es una materia ininteligible a la visión humana. En ello el movimiento y el tiempo se estalla o clausuran en los pliegues de lo visible, en las formas de lo aparente.

Volviendo al ejercicio interpretativo de Bertetto, éste al pensar la simulación como el ejercicio de copia sobre la copia de un diferencial del cual no tenemos noticias y concentrarse en identificar el estatuto simulacional de la imagen fílmica, entronca el dispositivo cinematográfico, sin plantearlo directamente, en una supuesta avanzada filosófica que pone en cuestión el mundo tangible, o como el mismo lo denomina el «mundo en sí» y que identifica como su primer valuarte al propio Nietzsche, citando uno de los fragmentos de «Voluntad de Poder» (1888). No obstante, Bertetto no da cuenta de los aportes críticos de la historiografía del simulacro hecha por Stoichita, donde expuso los dos caminos representacionales del arte occidental, el diferencial entre copia y fantasma, entre mimesis y simulación, entre Narciso y Pigmalión. Es decir, una serie de convenciones representacionales que permitirían leer el dispositivo cinematográfico dentro de una idea que supera al propio cine, es decir, una configuración de arte que se hará visible en una estadio específico de la modernidad y que se reproducirá en múltiples formas en su devenir.

Esto se hace evidente, cuando Bertteto analiza el dispositivo simulacional de la secuencia de transformación del personaje de Judy en Vertigo (1958), de Alfred Hitchcock, en términos muy similares al realizado por Stoichita, análisis que es el pilar estructural de su artículo «Imagen-simulacro». No obstante ello, en esta perspectiva es donde se encuentra enraizada la mayor densidad del concepto de imagen-simulacro que propone Bertteto, es decir, como potencia de la imagen fílmica, como estrategia de construcción dentro del lenguaje cinematográfico. En una suerte de fascinación por la construcción de 
estrategias narrativas simulacionales dentro del cine, en el engaño de identidades, en la extrañeza de la realidad fílmica y en el trastocamiento de las causalidades, que encuentra desde Blade Runner (1982), de Ridley Scott, Videodrome [Cuerpos invadidos] (1983), de David Cronenberg, y Minority Report [Sentencia previa] (2002), de Steven Spielberg, hasta en The Woman in the Window [La mujer en la ventana] (1944), de Fritz Lang, y Herr Tartüff [Tartufo] (1925), de Friedich W. Monrau. No es abusivo sospechar que será desde ahí que Bertetto proyecta el concepto de imagen-simulacro, privilegiando esta potencia por sobre otras, pero pareciese no ser suficiente para determinar el carácter ontológico del cine.

Para Bertetto, el simulacro cinematográfico construye una imagen demoníaca que sitúa la similitud en la exterioridad y vive de la diferencia con la realidad. Esta carencia de matices en el aparato interpretativo a propósito del concepto de simulacro, termina rescatando aquello que se pierde en el dispositivo cinematográfico, es decir, la realidad. Esto se ratifica en sus apreciaciones a propósito de la apariencia como mera ilusión, un espectro visible que carece de cualquier densidad, donde toda la gravedad de la realidad se ha ausentado. Acá encontramos el porqué de la lectura desilusionada del simulacro cinematográfico, ya que aún se reclama la pérdida de algo, aunque camuflada con cierto entusiasmo por las posibilidades de significación del cine, éste piensa el dispositivo cinematográfico en su tensión con la realidad y la imagen-simulacro (o deberíamos decir la imagen-cinematográfica) es la evidencia de que ya no podemos tener noticias de la realidad sino de su mera apariencia o ilusión, pero entendida ésta como falsedad o engaño.

El concepto de imagen-simulacro que edificamos en el libro, no refiere a un tipo de imagen cinematográfica particular, sino más bien al estatus epocal del cine contemporáneo, el cual ha desplazado la reflexividad del tiempo para privilegiar la densidad de la apariencia. El concepto de apariencia que perfilamos se distancia mucho a la idea de Bertetto de comprender a la apariencia como mera ilusión, es decir, el punto más lejano del ser, justamente cuando se camufla con sus formas visibles. Pero tampoco lo entendimos como el mero espectro visible de las cosas, sino en tanto mediación, como construcción significante de lo visible. En este sentido, la imagen-simulacro pensaría su reflexividad en las estrategias de articulación entre el «aparecer y su condición aparente», es decir, en aquello que se hace visible y cómo se hace visible. $Y$ en dicha intersección es donde toma conciencia de su simulación significante, ya que se le hace insostenible contener la densidad temporal de una modernidad que ha volcado en la inmediatez crónica el ritmo de su devenir. 
Lo fundamental, entonces, en la imagen cinematográfica, y que se hace irrevocablemente visible en la imagen-simulacro, no es si aquello que aparece en la imagen fue parte o no de una realidad anterior, si lo aparenta y con ello sostiene su engaño, como si lo pondera Bertetto cuando expone que "L'immagine filmica nella sua macro-artificialità, nella sua illusorietà strutturale è insieme un'immagine magica, un'immagine che gioca sistematicamente sulla differenza tra ciò che è e ciò che appare, e sull'artificiale e linnaturale che la costituiscono" (93), ya que en ello sigue existiendo la pretensión ontológica de determinar la naturaleza final del cine como sistema representacional, que para algunos se sostiene en su relación existencial con lo visible, como por ejemplo Andre Bazin, y para otros se sostiene en el engaño de lo visible, como Bertetto. Sino habría que posar la mirada en sus estrategias de construcción, sus operaciones de obra, es decir, sus dispositivos representacionales para pensar la densidad del movimiento, del tiempo y la apariencia, como se puede desprende del trabajo del propio Stoichita y, también, de Crary.

Por eso, también, nos distanciamos de la concepción discursiva del simulacro como puesta en crisis de la realidad, en la negación del acceso a ella, viviendo aún en la creencia de que algo hemos extraviado, que se desprende fundamentalmente del discurso de Baudrillard pero también de Perinola, donde el simulacro es el último estadio de la enajenación simbólica de la modernidad. Sino, más bien, lo entendimos como una disposición representacional que se concentra en su materialidad, a través de sus operaciones, dispositivos de obra y estrategias de significación. Mirado así, el simulacro no es el índice de pérdida de la realidad sino el tipo de relación con la realidad en la representación contemporánea en el arte, es decir, fantasmagórica y efímera. Con ello edifica el tipo de experiencia a la cual nos convoca, intraducible condición de momento nunca completo, nunca pleno en su existencia, siempre sujeto a su reactualización en la inmediatez del tiempo presente.

La imagen-simulacro, por ende, no es el reemplazo y negación de la realidad, sino la articulación discursiva de la apariencia en un sistema de simulación significante, que tiene sus rendimientos sobre la construcción de imágenes que trabajan sobre los imaginarios de lo sensible. Así erguimos un análisis materialista, donde el simulacro se entiende en su dimensión de artefacto de significación que se vuelca a desarrollar poéticas de lo sensible, visible y pensable. Donde la imagen-simulacro no es el mero resumidero de ciertas operaciones formales ni tampoco es la cristalización de la crítica al discurso moderno. Es justamente cuando la imagen audiovisual posa sus ojos sobre si

6 "La imagen fílmica en su macro-artificialidad, en su ilusoriedad estructural es al mismo tiempo una imagen mágica, una imagen que juega sistemáticamente sobre la diferencia que entre aquello que es, y aquello que aparenta ser, y sobre la artificialidad y la innaturalidad que la constituyen." 
misma en su condición de imagen, compleja, impura y abierta a las transformaciones que la modernidad le ha provocado a los dispositivos representacionales en la contemporaneidad. En definitiva, es la respuesta del cine a la pérdida de esa inocencia, cuando aún creía que podía contener en sus entrañas la representación del tiempo de la modernidad.

\section{Referencias bibliográficas}

Agamben, Giorgio (2008) «¿Qué es lo contemporáneo?». Salonkritik: $s / n$ de pp. Obtenido el 3 de mayo del 2009 en http://salonkritik.net/0809/2008/12/que_es_lo_contemporaneo_giorgi.php.

Badiou, Alain (2005) Imágenes y palabras: escritos sobre cine y teatro. Buenos Aires: Ediciones Manantial.

Bertetto, Paolo (2005) «La lágrima y el reflejo. Del análisis a la teoría del film». Revista cultural Trama y Fondo 19. pp. 7-20 - (2009) «L'immagine simulacro». Revista cultural Trama y Fondo 27.pp. 87-104

Crary, Jonathan (2008) Las técnicas del observador. Visión y modernidad en el siglo XIX. Murcia: Cendeac

De Baecque, Antoine (com.) (2006) Nuevos cine, nueva crítica: el cine en la era de la globalización. Barcelona: Editorial Paidós Ibérica.

Deleuze, Gilles (2001a) La Imagen-movimiento: Estudios sobre cine I. Barcelona: Ediciones Paidós Ibérica.

-------- (2001b) La Imagen-tiempo: Estudios sobre cine II. Barcelona: Ediciones Paidós Ibérica.

Krauss, Rosalind (2002) Lo fotográfico. Por una teoría de los desplazamientos. Barcelona: Editorial Gustavo Gili

Lipovetsky, Gilles y Serroy, Jean (2009) La pantalla global. Cultura mediática y cine en la era hipermoderna. Barcelona: Editorial Anagrama.

Rancière, Jacques. (2005) La fábula cinematográfica: Reflexión sobre la ficción en el cine. Barcelona: Ediciones Paidós Ibérica.

-------- (2010) Espectador emancipado. Buenos Aires: Ediciones Manantial.

Santa Cruz G., José M. (2008) El rostro cinematográfico. www.cybertesis.cl. Obtenido el 10 de marzo del 2009 en http://www.cybertesis.cl/tesis/uchile/2008/santacruz_j/ sources/santacruz_j.pdf.

(2010) Imagen-simulacro, estudios de cine contemporáneo (1). Santiago: Ediciones Metales Pesados.

Stoichita, Victor I. (2006) Simulacros. El efecto Pigmalión: de Ovidio a Hitchcock. Madrid: Ediciones Siruela. 